\title{
Prediabetes and cardiovascular complications study (PACCS): international collaboration 4 years' summary and future direction
}

\author{
E. U. Nwose ${ }^{1,2,3^{*}}$ (1) R. S. Richards ${ }^{1}$, P. T. Bwititi ${ }^{4}$, E. O. Igumbor ${ }^{2}$, E. J. Oshionwu ${ }^{3,5}$, K. Okolie ${ }^{3}$, I. C. Onyia ${ }^{3,6}$, \\ A. Pokhrel' ${ }^{7}$ P. Gyawali 8 , J. N. Okuzor ${ }^{3,9}$, V. M. Oguoma ${ }^{10}$, F. W. Gardiner ${ }^{1,11}$ and L. Wang ${ }^{4}$
}

\begin{abstract}
Objective: The prediabetes and cardiovascular complications studies proposes to develop a screening protocol for diabetes cardiovascular risk, and strategies for holistic management amongst others. Over 500 participants were recruited in the first 2 years of rural community research screening. Specific for this report, various published findings were reviewed. The objective is to summarize research outcomes and itemize limitations as they constitute basis of future directions.

Results: Affordability and availability are major confounding behavioural change wheel factors in the rural community. 4.9\% prevalence of prediabetes, which may be lower or non-significantly different in urban areas. Hyperglycaemia co-morbidity with dyslipidaemia (5.0\%), obesity (3.1\%) and hypertension (1.8\%) were observed. Limitation of the study includes participants being mostly over 60 years old, which has created impetus for the Global Alliance on Chronic Diseases agenda on vulnerability of older adults to diabetes being a new direction of the collaboration. Other directions in Australia and Nepal focus on patients with chronic kidney disease with or without cardiovascular complications. This report highlights the need to translational research.
\end{abstract}

Keywords: Cardiovascular complications, Diabetes mellitus, Early identification and intervention, Holistic healthcare management, Low-mid income countries, Prediabetes, Public health

\section{Introduction}

\section{The original research proposal}

Cardiovascular risk assessment in prediabetes and undiagnosed diabetes mellitus study has been identified as necessary, especially for low-mid income communities [1]. To substantiate the discussion of prediabetes and cardiovascular disease (CVD), a systematic review had been performed that provided insight, for instance, the need to study rural communities where lifestyles are different from the urban areas [2]. Suffice to say that some of the burdens or deaths associated with CVD are

\footnotetext{
*Correspondence: enwose@csu.edu.au

${ }^{1}$ School of Community Health, Faculty of Sciences, Charles Sturt University, Orange Campus, Leeds Parade, Orange, NSW, Australia Full list of author information is available at the end of the article
}

preventable since they are due to avoidable risk factors such as unhealthy diet, physical inactivity and smoking [3]. In particular, the global burdens of CVDs is rife (Fig. 1) [4-6]. As published [1], the aims of the 'prediabetes and cardiovascular complications studies (PACCS) collaboration initiative are:

1. Diagnosis, management and monitoring of diabetes mellitus (DM) pathogenesis by laboratory methods.

2. Early and holistic intervention in DM pathogenesis in the perspective of health education as well as lifestyle changes.

3. Support system for allied healthcare professionals' integration in the prediabetes care team. 


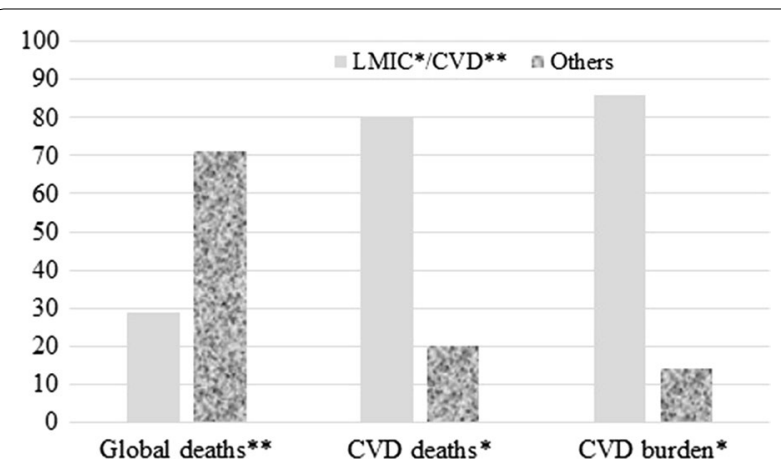

Fig. 1 Estimated global burden and deaths due to CVD. *Deaths due to CVD vs. other diseases [4]; **LMIC vs. developed countries $[5,6]$

\section{The proposed research design}

The study is designed to be in three phases. The first phase is to identify prediabetes and undiagnosed diabetes through population screening exercise. The second and third phases will be longitudinal studies involving participants identified in the first phase as having prediabetes without dyslipidaemia, or clinically established cardiovascular disease. The second phase shall focus on preventive management including evaluation of the use of exercise, and nutrition. The third phase will include probing the development of diabetes and CVD with a view to develop a model chart for the assessment of CVD risk in prediabetes [1].

In terms of significance of the research agenda, suffice to highlight with the quote that

\section{"Diabetes is a main ticking time bomb out there in low- and middle-income countries ... that don't have the health-care infrastructure ... need to start to tackle these problems now" [7]. That is, given the lack of data on the burden of disease, espe- cially among the unsearched rural communities of low-mid income countries (LMIC) means lack of evidence for policy makers to make the health ser- vices unavailable, a research program focusing on this issue is imperative. For this reason, the PACCS agenda has been designed to occur in phases as ongoing since 2013.}

\section{The objective of this report}

The purpose of this report is to present a summary of our research outcomes since the beginning in 2013, including how the limitations encountered so far have formed basis for future directions.

\section{Main text}

\section{Methods}

Volunteers recruited included 74 collected in 2013 [3, $8]$, and 422 collected in 2014 [9, 10]; which have been analysed and reported. Another volunteers of 2015 and 2016 have been screened and still being analysed. Body mass index (BMI), blood pressure and waist circumference, blood glucose level, and lipid profile were measured. The Stanford Patient Education Research Centre questionnaire was used to collect data on knowledge, attitude and practice (KAP) based on established formats $[3,8]$; while and World Health Organisation (WHO) Global Physical Activity questionnaire was used to access physical activity domains amongst others.

In all cases of data collection, purposive recruitment of participants were by invitation for public health lectures in health facilities and at schools, after which, inclusion of volunteers was based on consent to participate and being $\geq 18$ years old. Clinical assessments and laboratory tests were carried out according to standard operational procedures in the health facilities. Different inferential statistics were adopted in the various pieces of studies. For instance:

KAP analysis on 'questions about lifestyle, occupational backgrounds and visiting healthcare facilities' involved "determining percentage of participants whose health status require healthcare", by stratifying participants' opinion on their general health condition, and then cross-checking with responses on the questionnaire regarding visiting clinic and/or monitoring for CVD risk factors they have performed or have been done on them" [3]. Preliminary study on metabolic syndrome and prediabetes also involved determination of percentage prevalence based on (and comparison of) commonest three criteria-Third Adult Treatment Panel, International Diabetes Federation, and WHO [8]. Prevalence of cardiovascular disease risk factors among a Nigerian adult population: relationship with income level and accessibility employed WHO STEP wise questionnaire to generate socioeconomic data of the participants, amongst others. "Multivariate analyses were performed to assess any difference between the geographical locations and SES indicators, and prevalence of CVD risk factors and access to CVD risk screening" [9].

In the association of physical activity with metabolic syndrome, 'World Health Organisation (WHO) Global Physical Activity Questionnaire' was adopted. Inferential statistics involving "Cross-tabulation between dichotomous variables of total physical activity and metabolic syndrome risk factors, education, work status and income status were generated to assess the prevalence of physical activity/inactivity across the different socio-demographic/economic variables and metabolic syndrome risk factors" [10]. In the evaluation of Cardiovascular disease risk factors in a Nigerian population with impaired fasting blood glucose level 
and diabetes mellitus, optimal discriminant analysis and 'Hierarchical Optimal Classification Tree Analysis' was employed [11]. More details on these research methods including statistics analyses were as published $[3,8-11]$.

\section{Results: synopsis of 4 years research outcome}

The following numbered points are some of the results summaries of various research outcomes since the last 4 years. The first three are on 'screening and evaluation of prevalence-phase 1 of study', while the forth is in view of phase 2 of the research program. For the purpose of a 'summary update', these results are from several studies has provided with reference to where each report has been published.

1. Prediabetes: The preliminary observation of prediabetes was $6 \%$ in females compared to $3 \%$ in males, but the overall prevalence of metabolic syndrome (MS) was less in females than males [8]. Further data collection showed no statistical difference between gender groups [9]. There is estimated $6.4 \%$ prevalence of prediabetes in the rural community [9], which may be higher or non-significantly different in urban areas (Fig. 2). Collaborative consolidated data indicate overall prevalence of 5.8\% impaired fasting glucose and $3.1 \%$ diabetes [11].

2. Prevalence of hypertriglyceridaemia and hypo-HDL observed in 2013 compared to 2014 were not exactly the same. Here, we report that prevalence of abnormal HDL-cholesterol, total cholesterol and triglycer- ide averaged 22, 45 and 37\%, respectively (Additional file 1) $[8,9]$. The gender differences in prevalence are reflected in average levels in Fig. 2.

3. Percentage of population with and without prior assessment vs. prevalence: first, over $70 \%$ of the participants in the rural community are yet to have health check or screening for DM and CVD risk [3]. This indicates proportion of participants in the population without priori assessment of MS. Second, in terms of CVD risk factors associated with IFG, comorbidity with dyslipidaemia (5.0\%) was the highest followed by obesity (3.1\%) and hypertension (1.8\%) [11]. Relative to the first point, this indicates prediabetic participants with MS (Table 1).

4. Physical activities: analysis indicates that women are significantly less physically active than men (Fig. 2) $[3,10]$.

The results in Table 1 show, for instance, that only $13.5 \%$ have assessed their diabetic status while there is up to 5.8 prevalence of prediabetes that could benefit from early intervention. Or in other words, that $78 \%$ participants are yet to assess their dyslipidaemia status whereas among those who assessed, there is 2.6 and $4.8 \%$ comorbidity with diabetes and prediabetes, respectively.

\section{Discussion}

A major finding being reported in this summary is that the prevalence of prediabetes in the rural community is much higher than speculated. We have reported on CVD risk assessment in prediabetes and undiagnosed

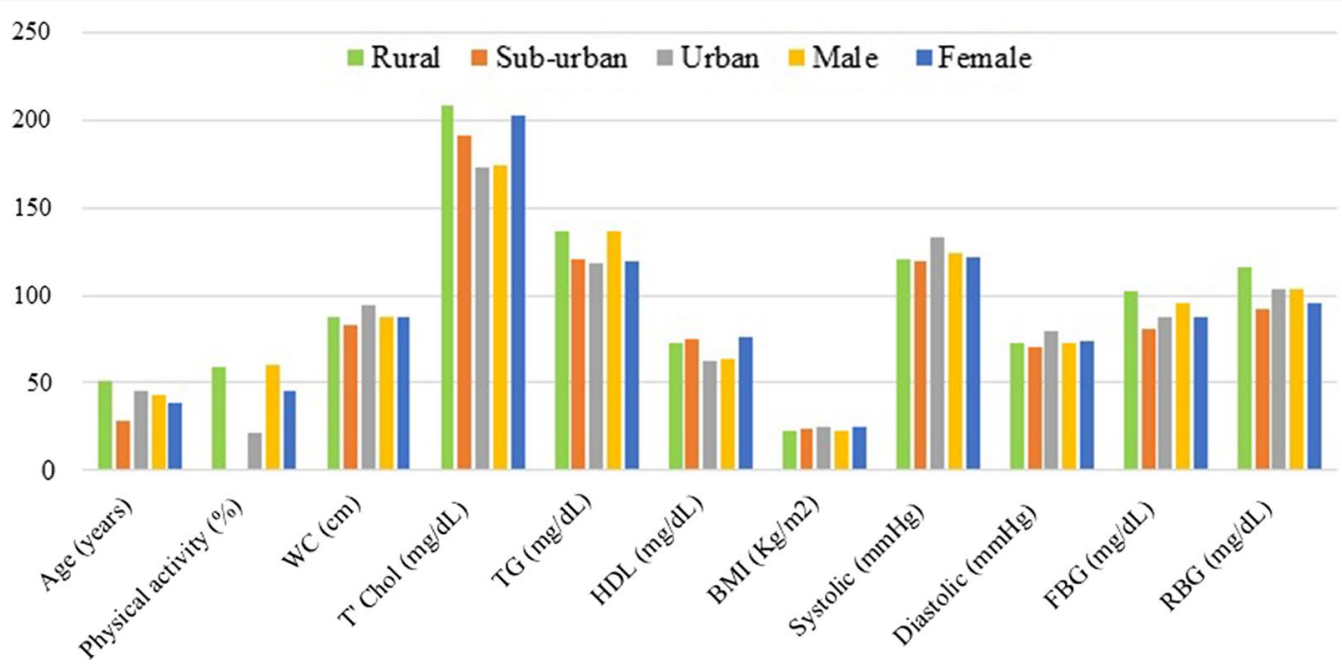

Fig. 2 Comparisons of average levels anthropometric and biochemical parameters between gender group and 'rural vs. urban clusters' 
Table 1 Prevalence (\%) of participants with prior assessment vs. DM and MS factors

\begin{tabular}{llll}
\hline & Yes & No & Unsure \\
\hline Prior assessment $^{\mathrm{a}}$ & & & \\
Blood sugar level & 13.5 & 74.3 & 12.2 \\
$\begin{array}{l}\text { Lipid profile } \\
\text { Overweight }\end{array}$ & 8.1 & 78.4 & 13.5 \\
Prevalence $^{\mathrm{b}}$ & 1.4 & 85.1 & 13.5 \\
$\quad$ Prediabetes only & 5.8 & 94.2 & Not applicable \\
Diabetes only & 3.1 & 96.9 & \\
Diabetes + dyslipidaemia & 2.6 & 97.4 & \\
$\quad$ Diabetes + hypertension & 1.9 & 98.1 & \\
Diabetes + obesity & 2 & 98 & \\
Prediabetes + dyslipidaemia & 4.8 & 95.2 & \\
Prediabetes + hypertension & 2.6 & 97.4 & \\
Prediabetes + obesity & 3.1 & 96.9 & \\
\hline
\end{tabular}

a Participants with or without prior assessment [3]

b Prevalence rates based on research data [11]

diabetes mellitus (UDM) in Nigeria [1]. Appropriate glycaemic control is crucial to delay or prevent the progression of diabetes [12], and a few points are pertinent to emphasize, which made this report update imperative.

1. Both physical inactivity and prediabetes appear higher in the women by comparison with men in the study area (Fig. 2), and such observations can serve as basis for gender specific diabetes education and exercise regimen.

2. Higher prevalence of diabetes and prediabetes in the rural community (Fig. 2); disagrees with data of the Diabetes Association of Nigeria that indicates a $<1 \%$ prevalence in a particular rural community and 11\% in urban Lagos [13], but agrees with another report from the United States that the disease may be more prevalent in rural communities [14]. Perhaps, in future discourse and research on rural-urban disparities, recourse should be made to the genetic make-up of subpopulations compared. For instance, in our study, the urban subpopulation comprised of individuals of the same Ukwani ethnicity as the rural community.

3. Prevalence of dyslipidaemia and/or obesity (Fig. 2; Table 1) indicates that relatively equal number $(<5 \%)$ of the people in the Nigeria require only lipid or BMI model of cardiovascular screening, while over 95\% may benefit from either of the two models. This is relevant for service delivery, especially as lipid profile testing is mostly unaffordable.
In addition to diabetes whose incidence is on the rise, there is the issue of oxidative stress, which is a CVD risk factor that is common in LMIC such as Nepal and Nigeria [15-18]. There is scientific underpinning for exercise therapy and nutrition to manage and prevent oxidative stress in diabetes [19-21] thus CVDs. Given our observation on physical activities, lifestyle changes for stress management and the behavioural change wheel remains one of our research in phase two.

CVD is established as a leading contributor to the burden of diseases and mortality [6,22], and estimated figures are presented (Fig. 1). Some of the burdens or deaths are preventable since they are due to avoidable risk factors such as unhealthy diet, physical inactivity and smoking [3]. Yet, there is paucity of reports on DM and dyslipidaemia, and where the reports are available they are based on studies in urban areas [2]. Thus, it is important to equally focus research in urban and rural areas.

In conclusion, this study seeks how best to tackle diabetes problem in rural communities of LMIC. This summary emphasizes the prevalence of diabetes and prediabetes in LMIC being higher than speculated. The report highlights the need for translational research in rural communities to enhance management of DM and its CVD complications; as well as indicates the prospect of international collaborations.

\section{Limitations}

Every research sampling method has merits and demerit. In this occasion, the purposive, but convenience recruitment method creates its own bias such as sample size. Consciousness of such bias necessitated the invitation of other researchers for synergistic consolidated data analysis [23]. The three limitations that constitute basis for future research directions are worthy of mention here, and will be elaborated in supplementary document (Additional file 2).

Firstly, there is albeit better-than-expected good health of the Nigerian rural population viz: the prevalence of prediabetes observed is less than hypothesized. The implication is that recruitment into phase 2 and 3 of original proposal is slow. These limitations have led to the future direction involving a proposal of the consortium in Nepal whose broad objective is assessment of CVD complications in CKD patients undergoing haemodialysis through routinely measured laboratory parameters.

Secondly, in the original proposal, 3 centres were identified for data collection. Lack of funding as well as logistics resulted in data collection only occurring in the Nigerian centre. However data collection has now started in Australia, as was the intention. The proposal was that data can be extracted from the electronic medical records to determine. The future direction is whether the targets 
on blood pressure and/or glycaemic control in patients with CKD and diabetes are met, respectively; as well as if blood viscosity changes correlates with glycated haemoglobin levels.

Thirdly, in the Nigerian centre where screening is occurring, consent and participation has been mostly by the older adults. This limitation has provided impetus to develop proposal for studying increased vulnerability of older adults to DM and its CVD complications [24], in line with Global Alliance on Chronic Diseases agenda. An expatiation of these three future research directions are presented in supplementary document (Additional file 2-future directions').

\section{Additional files}

Additional file 1. 2 years' (2013 and 2014) data on observed prevalence* of lipidaemia. The observation of prevalence of dyslipidaemia in 2014 was apparently different from the preliminary data of 2013. Given the study is the same community, but different cohort of volunteer participant, this table presents the averages for the 2 years data.

Additional file 2. Revision of proposal — three future research directions. This article is founded on the premise of ongoing research activities whereby there are additional research directed, which could not be contained within the words limit of this journal policy. Additional file 2 is a 'supplementary' provision for the extra information, instead of publishing it as a 2nd (albeit short) paper in another journal.

\section{Abbreviations}

BMI: body mass index; CKD: chronic kidney diseases; CVD: cardiovascular disease; DM: diabetes mellitus; HDL: high density lipoprotein cholesterol; KAP: knowledge, attitude and practice; LMIC: low-mid income countries; MS: metabolic syndrome; PACCS: prediabetes and cardiovascular complications studies; WHO: World Health Organization

\section{Authors' contributions}

EUN conceptualized the PACCS study with support of RSR and PTB. EJO and ICO partnered with EUN in conceptualizing the LMIC's community assessment need component. Also, EJO has been the Director of Ethics compliance, while ICO is the Medical Director of research program in Nigeria and KO is Medical Officer at the Catholic Hospital performance location. VMO contributed to results generated from Nigeria, while JNO re-articulated some of the future research directions. EOI has been leading Public and Community Health of Novena University consortium. AP and PG developed the proposal for Nepal consortium. LW, PTB, FWG and EUN developed the proposal for Australia consortium. All authors read and approved the final manuscript.

\footnotetext{
Author details

1 School of Community Health, Faculty of Sciences, Charles Sturt University, Orange Campus, Leeds Parade, Orange, NSW, Australia. ${ }^{2}$ Public \& Community Health Department, Novena University, Ogume, Kwale, Nigeria. ${ }^{3}$ Global Medical Research \& Development Organization, Catholic Hospital Abbi, Albury, NSW, Australia. ${ }^{4}$ School of Biomedical Sciences, Faculty of Sciences, Charles Sturt University, Wagga Wagga, NSW, Australia. ${ }^{5}$ California Department of State Hospital, Stockton, CA 95215, USA. ${ }^{6}$ Onyx Hospital \& Maternity, Lagos, Nigeria. ${ }^{7}$ Nepal Medical College \& Teaching Hospital, Kathmandu, Nepal. ${ }^{8}$ University of Montreal, Montreal, Canada. ${ }^{9}$ Laboratory Department, Texas Health Resources (HMH-HEB), Bethesda, TX 76022, USA. ${ }^{10}$ School of Psychological \& Clinical Sciences, Charles Darwin University, Wagga Wagga, NSW, Australia. ${ }^{11}$ Calvary Public Hospital, Bruce, ACT, Australia.
}

\section{Acknowledgements}

Data collection in 2014 benefitted in part from Ph.D. work of Victor Oguoma that was done through Charles Darwin University. The managements of Catholic Hospital Abbi, Friends Laboratory Ltd. Obiaruku, Novena University Ogume and Onyx hospital Ltd Lagos are hereby acknowledged for enabling the sustainability of the project. EU Nwose continues to enjoy yearly permission of overseas travels to enable dedication to this work, for which the management and colleagues at School of Community Health are hereby acknowledged. This paper is an expanded version of abstract presented at the IDF congress 2017

\section{Competing interests}

The authors declare that they have no competing interests.

\section{Availability of data and materials}

The datasets used and/or analysed during the current study are available from the corresponding author on reasonable request.

\section{Consent for publication}

Not applicable.

\section{Ethics approval and consent to participate}

This study was approved by the Human Research Ethics Committee of the Charles Sturt University Australia, as well as Novena University Nigeria. Prior to the Universities ethical approval was a clearance from the health department of Ndokwa West local government area of Delta State Nigeria. Consented to participate was written.

\section{Funding}

This project has yet to receive funding for direct costs. Progress has been mainly by self-funding by the principal investigator, EU Nwose, with some support from RS Richards. EU Nwose was awarded Charles Sturt University 'Faculty of Science' 1 year Research Fellowship grant to buy-out time for some teaching relief, which enabled this publication.

\section{Publisher's Note}

Springer Nature remains neutral with regard to jurisdictional claims in published maps and institutional affiliations.

Received: 28 July 2017 Accepted: 28 November 2017

Published online: 11 December 2017

\section{References}

1. Nwose EU, Richards RS, Digban K, Bwititi PT, Ennis G, Yee KC, Oguoma VM, Liberato S. Cardiovascular risk assessment in prediabetes and undiagnosed diabetes mellitus study: international collaboration research overview. North Am J Med Sci. 2013;5:625-30.

2. Oguoma VM, Nwose EU, Richards RS. Prevalence of cardio-metabolic syndrome in Nigeria: a systematic review. Public Health. 2015;129:413-23.

3. Oguoma VM, Nwose EU, Bwititi PT. Cardiovascular disease risk prevention: preliminary survey of baseline knowledge, attitude and practices of a nigerian rural community. North Am J Med Sci. 2014;6:466-71.

4. World Health Organization. Global atlas on cardiovascular disease prevention and control. 2011;9-12. (http://www.who.int/cardiovascular_diseases/publications/atlas_cvd/en/\#). Accessed 9 July 2014.

5. Ikem I, Sumpio BE. Cardiovascular disease: the new epidemic in subSaharan Africa. Vascular. 2011;19:301-7.

6. Uchenna DI, Ambakederemo TE, Jesuorobo DE. Awareness of heart disease prevention among patients attending a specialist clinic in Southern Nigeria. Int J Prev Treat. 2012;1:40-3. https://doi.org/10.5923/j. ijpt.20120103.01.

7. Frood A. Funding: global alliance for chronic diseases tackles diabetes. Lancet. 1014;2013:382.

8. Nwose EU, Oguoma VM, Bwititi PT, Richards RS. Metabolic syndrome and prediabetes in ndokwa community of Nigeria: preliminary study. North Am J Med Sci. 2015;7:53-8. 
9. Oguoma VM, Nwose EU, Skinner TC, Digban KA, Onyia IC, Richards RS. Prevalence of cardiovascular disease risk factors among a Nigerian adult population: relationship with income level and accessibility to CVD risks screening. BMC Public Health. 2015;15:397.

10. Oguoma VM, Nwose EU, Skinner TC, Richards RS, Digban KA, Onyia IC. Association of physical activity with metabolic syndrome in a predominantly rural Nigerian population. Diabetes Metab Syndr. 2016;10:13-8.

11. Oguoma VM, Nwose EU, Ulasi II, Akintunde AA, Chukwukelu EE, Bwititi PT, Richards RS, Skinner TC. Cardiovascular disease risk factors in a Nigerian population with impaired fasting blood glucose level and diabetes mellitus. BMC Public Health. 2017:17:36.

12. Wang-Sattler R, Yu Z, Herder C, Messias AC, Floegel A, He Y, Heim K, Campillos M, Holzapfel C, Thorand B, et al. Novel biomarkers for prediabetes identified by metabolomics. Mol Syst Biol. 2012;8:615.

13. Diabetes Association of Nigeria. Diabetes education and prevention, 2 nd ed. Nigeria; 2013. http://diabetesnigeria.org/diabetes-education-andprevention/. Accessed 28 May 2017.

14. O'Connor A, Wellenius $G$. Rural-urban disparities in the prevalence of diabetes and coronary heart disease. Public Health. 2012;126:813-20.

15. Dulal HP, Lamsal M, Sharma SK, Baral N, Majhi SS. Status of iron, oxidant and antioxidants in chronic type 2 diabetes mellitus patients. Nepal Med Coll J. 2014:16:54-7.

16. Shrestha S, Chandra L, Aryal M, Das BK, Pandey S, Baral N. Evaluation of lipid peroxidation and antioxidants' status in metabolic syndrome. Kathmandu Univ Med J (KUMJ). 2010;8:382-6.

17. Maharjan BR, Jha JC, Adhikari D, Risal S, Alurkar VM, Singh PP. Oxidative stress, antioxidant status and lipid profile in ischemic heart disease patients from western region of Nepal. Nepal Med Coll J. 2008;10:20-4.
18. Odum EP, Ejilemele AA, Wakwe VC. Antioxidant status of type 2 diabetic patients in Port Harcourt, Nigeria. Niger J Clin Pract. 2012;15:55-8.

19. Naderimagham S, Niknami S, Abolhassani F, Hajizadeh E, Montazeri A. Development and psychometric properties of a new social support scale for self-care in middle-aged patients with type II diabetes (S4-MAD). BMC Public Health. 1035;2012:12.

20. Noroozi A, Ghofranipour F, Heydarnia AR, Nabipour I, Shokravi FA. Validity and reliability of the social support scale for exercise behavior in diabetic women. Asia Pac J Public Health. 2011;23:730-41.

21. Gordon L, Morrison E, McGrowder D, Young R, Fraser Y, Zamora E, Alexander-Lindo R, Irving R. Effect of exercise therapy on lipid profile and oxidative stress indicators in patients with type 2 diabetes. BMC Complement Altern Med. 2008;8:21. https://doi.org/10.1186/1472-6882-8-21.

22. Lopez AD, Mathers CD, Ezzati M, Jamison DT, Murray CJ. Global and regional burden of disease and risk factors, 2001: systematic analysis of population health data. Lancet. 2006;367:1747-57.

23. Oguoma VM, Nwose EU, Ulasi II, Akintunde AA, Chukwukelu EE, Araoye MA, Edo AE, ljoma CK, Onyia IC, Ogbu II, et al. Maximum accuracy obesity indices for screening metabolic syndrome in Nigeria: a consolidated analysis of four cross-sectional studies. Diabetes Metab Syndr. 2016;10:121-7.

24. Nwose EU, Bwititi PT, Richards RS. Increased vulnerability of older adults to DM and its CVD complications: proposal for assessment, management and monitoring by diagnostic methods. Int J Res Med Sci. 2015;3:810-6.

\section{Submit your next manuscript to BioMed Central and we will help you at every step:}

- We accept pre-submission inquiries

- Our selector tool helps you to find the most relevant journal

- We provide round the clock customer support

- Convenient online submission

- Thorough peer review

- Inclusion in PubMed and all major indexing services

- Maximum visibility for your research

Submit your manuscript at www.biomedcentral.com/submit 